\title{
Effect of Functionalization of Reduced Graphene Oxide Coatings with Nitrogen and Sulfur Groups on Their Anti-Corrosion Properties
}

\author{
Karolina Ollik $^{1, * \mathbb{D}}$, Jakub Karczewski ${ }^{2}$ and Marek Lieder ${ }^{1}$ (D) \\ 1 Department of Process Engineering and Chemical Technology, Faculty of Chemistry, \\ Gdansk University of Technology, 11/12 Gabriela Narutowicza Street, 80-233 Gdansk, Poland; \\ lieder@pg.edu.pl \\ 2 Department of Solid State Physics, Faculty of Applied Physics and Mathematics, Gdansk University of \\ Technology, 11/12 Gabriela Narutowicza Street, 80-233 Gdansk, Poland; jakub.karczewski@pg.edu.pl \\ * Correspondence: karolina.ollik@pg.edu.pl; Tel.: +48-58-347-1275
}

check for updates

Citation: Ollik, K.; Karczewski, J.;

Lieder, M. Effect of Functionalization of Reduced Graphene Oxide Coatings with Nitrogen and Sulfur Groups on Their Anti-Corrosion Properties. Materials 2021, 14, 1410. https:// doi.org/10.3390/ma14061410

Academic Editor: Giorgio Speranza

Received: 1 February 2021

Accepted: 11 March 2021

Published: 14 March 2021

Publisher's Note: MDPI stays neutral with regard to jurisdictional claims in published maps and institutional affiliations.

Copyright: (C) 2021 by the authors Licensee MDPI, Basel, Switzerland. This article is an open access article distributed under the terms and conditions of the Creative Commons Attribution (CC BY) license (https:/ / creativecommons.org/licenses/by/ $4.0 /)$.

\begin{abstract}
Electrophoretic production of anticorrosion carbonaceous coatings on copper could be successfully performed by anodic oxidation of negatively charged graphene platelets suspended in an aqueous solution. The various platelets were synthesized by Hummer's method followed by a hydrothermal reduction in the presence of $\mathrm{NH}_{4} \mathrm{SCN}$ which was expected to substitute some parts of graphene structure with nitrogen and sulfur groups. X-ray photoelectron spectroscopy analysis confirmed that the graphene precursors, as well as the coatings, contained typical nitrogen groups, such as pyridinic and pyrrolic, and sulfur groups, such as thiol, thiophene, or $\mathrm{C}-\mathrm{SO}_{2}$. However, due to oxidation during deposition, the qualitative and quantitative composition of the graphene coatings changed relative to the composition of the precursors. In particular, the concentration of nitrogen and sulfur dropped and some thiophene groups were oxidized to $\mathrm{C}-\mathrm{SO}_{2}$. Studies showed the functionalized coatings had a uniform, defect-free, hydrophobic, more adhesive surface than nonmodified films. The corrosion measurements demonstrated that these coatings had better protective properties than the ones without these heteroatoms. This behavior can be assigned to the catalytic activity of nitrogen towards oxidation of $\mathrm{C}-\mathrm{SO}_{2}$ groups to $\mathrm{C}-\mathrm{SO}_{3} \mathrm{H}$ with oxygen.
\end{abstract}

Keywords: heteroatoms; coatings; hydrophobicity; corrosion resistance

\section{Introduction}

Graphene and its various oxidized or chemically functionalized forms have been recently studied as monolayers or multicomponent coatings for corrosion protection of metals. Graphene possesses properties that are beneficial for metal protection, such as chemical resistance, mechanical endurance, good adhesion to metals, or impermeability to gases and water. On the other hand, the conducting graphene layers might accelerate the corrosion in some instances [1]. Moreover, under ambient conditions, metal crystallographic orientation (especially for copper) is dominant to determine the degree of oxidation of substrate beneath graphene [2]. Deposition of the impeccable graphene coatings on a metal substrate is a rather challenging task. It can be carried out either from gaseous or aqueous phases, of which the first one, chemical vapor deposition, is essentially dedicated to the formation of (unoxidized) graphene layers [3-5]. Hence, the aqueous deposition seems to be more versatile, because the various chemically transformed entities of graphene, e.g., oxidized or doped, can be used as precursors, provided they are dispersible in water. The method of choice for this approach is electrophoretic deposition (EPD). It is a peculiarity of EPD that the composition of the coating differs from that of graphene precursor in a solution. One of the graphene precursors can be reduced graphene oxide (rGO). It is used, amongst other things, in photocatalytic hydrogen production and supercapacitors [6], electrochemical sensors [7], enhancement of four-electron transfer-assisted oxygen reduction, and 
methanol oxidation reaction [8]. Compared to rGO, graphene oxide is a more frequently used precursor in the fabrication of anticorrosion films. It is electrochemically active, and therefore, undergoes reduction (welcomed process) or oxidation (unwelcomed) at the electrode surface. Additionally, if the deposition takes place on an anode, some cations, due to limited metal dissolution, might be trapped in the graphene layer. Graphene oxide contains a relatively large amount of various oxygen groups, e.g., hydroxyl or carboxylic, which facilitate the dispersion in water. Some of these groups separate from the graphene skeleton as $\mathrm{CO}_{2}$ during electrodeposition [9]. This is an expected outcome from a corrosion protection perspective because the coating becomes less hydrophilic. On the other hand, the reduced content of oxygen in the coating does not lead to the restoration of an intact graphene structure (some carbon atoms in the evolution $\mathrm{CO}_{2}$ come from graphene structure). Nevertheless, the coatings probably contain a number of intact graphene domains, which might be current conductive. One can visualize such coatings as the one composed of three domains: pure graphene (current-conducting), oxidized graphene (hydrophilic, but still impermeable to oxygen or water), and defects or holes that do not protect the metal surface. Once graphene oxide is employed as the EPD precursor, we end up with coatings that do not meet the criteria of good protective properties [10-12]. There are at least two techniques for solving this problem. First, we consider multilayer (consecutive) deposition, a well-known protocol adopted to tackle the porosity of nickel coatings, as not scientifically challenging and, second, a substitution of a small percentage of carbon atoms in the graphene precursors with nitrogen. There are numerous published reports confirming the presence of pyridinic, pyrrolic, and other nitrogen-based groups in N-substituted graphene. Kumar et al. reported corrosion resistance results from hydrophobic and intact surfaces compared to rGO and GO coatings [13]. In turn, in another case, the good protective properties of nitrogen-doped coatings were caused by low conductivity and continuous surfaces [14]. However, these structures were supposed to catalyze oxygen reduction [15], which they seemingly did, a role we do not expect nitrogen to play as far as the protective layers are concerned. We decided to follow this route because nitrogen groups might add a promising feature to the graphene coatings-i.e., disruption of electron transfer across the graphene domains. Our expectations were partly confirmed. N-substituted graphene oxides produced coatings that performed better than unsubstituted ones. However, in the conclusion, we write that protection would have been better if nitrogen groups had not catalyzed oxygen reduction [16]. Indeed, we found that the presence of nitrogen groups in the graphene coatings is generally beneficial for corrosion protection, but still, we have tried to figure out how to block the noxious effect of nitrogen catalytic activity. We came up with the idea of sulfur codoping because there were a couple of reports on catalytic oxidation of gaseous $\mathrm{SO}_{2}$ to $\mathrm{SO}_{3}$ over $\mathrm{N}$-doped graphene $[17,18]$. We hoped that it would be also possible to oxidize $\mathrm{C}-\mathrm{SO}_{2}$ to $\mathrm{C}-\mathrm{SO}_{3} \mathrm{H}$ with oxygen (from the air) penetrating the $\mathrm{N}$-doped graphene coatings. As a matter of fact, this reaction also involves oxygen reduction, but the electrons are donated by sulfur not metal, thus it may diminish corrosion.

Nitrogen- and sulfur-functionalized reduced graphene oxide coatings as the anticorrosion layer have not been reported yet. In the present work, graphene oxide, reduced graphene oxide, and nitrogen- and sulfur-functionalized reduced graphene oxide were synthesized by an improved Hummer's method, one-step hydrothermal method, and one-step hydrothermal method in presence of ammonium thiocyanate, respectively. Subsequently, the obtained products were electrophoretically deposited on the copper substrate and subjected to numerous studies, revealing their properties.

\section{Materials and Methods}

\subsection{Reagents}

Copper sheets (purity: 99.99\%, size $10 \times 15 \mathrm{~mm}$, thickness: $1 \mathrm{~mm}$, not annealed), graphite powder (325 mesh, purity: 99.9995\%, Alfa Aesar, Haverhill, MA, USA), potassium permanganate $\left(\mathrm{KMnO}_{4}\right.$, purity: $99.0 \%, \mathrm{POCH}$, Gliwice, Poland), orthophosphoric acid $\left(\mathrm{H}_{3} \mathrm{PO}_{4}, 85 \%, \mathrm{POCH}\right)$, sulfuric acid $\left(\mathrm{H}_{2} \mathrm{SO}_{4}, 95 \%, \mathrm{POCH}\right)$, hydrogen peroxide $\left(\mathrm{H}_{2} \mathrm{O}_{2}, 30 \%\right.$, 
CHEMPUR, Piekary Slaskie, Poland), ethanol $\left(\mathrm{C}_{2} \mathrm{H}_{5} \mathrm{OH}, 96 \%\right.$, $\left.\mathrm{POCH}\right)$, hydrochloric acid $(\mathrm{HCl}, 35-38 \%, \mathrm{POCH})$, acetone $\left(\left(\mathrm{CH}_{3}\right)_{2} \mathrm{CO}, \mathrm{POCH}\right)$, ammonium thiocyanate $\left(\mathrm{NH}_{4} \mathrm{SCN}\right.$, purity: $99.0 \%, \mathrm{POCH})$, and sodium chloride $(\mathrm{NaCl}$, purity: $99.5 \%, \mathrm{POCH})$ were used.

\subsection{Synthesis of Graphene Oxide}

Graphene oxide was synthesized by the improved Hummer's method [19]. Concentrated sulfuric and phosphoric acids in a ratio of 9:1 were added to a round bottom flask containing $6 \mathrm{~g} \mathrm{KMnO}_{4}$ and $1 \mathrm{~g}$ graphite powder. Then, the solution was heated to ca. $70{ }^{\circ} \mathrm{C}$ and stirred overnight. After cooling to room temperature, the solution was mixed with $200 \mathrm{~g}$ ice and $1 \mathrm{~mL} \mathrm{H}_{2} \mathrm{O}_{2}$, then filtrated under vacuum and finally washed with $250 \mathrm{~mL}$ water, $250 \mathrm{~mL}$ concentrated $\mathrm{HCl}$, and two times with $250 \mathrm{~mL}$ ethanol. After each washing step, the solid was separated by centrifugation (6000 rpm for $15 \mathrm{~min})$. At the end, the precipitate was washed with acetone, which was then evaporated, leaving around $1 \mathrm{~g}$ of a brown solid.

\subsection{Synthesis of Reduced Graphene Oxide}

The one-step hydrothermal method was used for the preparation of reduced graphene oxide [20]. In total, $200 \mathrm{mg}$ GO was dispersed in $40 \mathrm{~mL}$ of distilled water by using an ultrasonic bath for $30 \mathrm{~min}$. Then, the solution was placed in stainless steel autoclave and subjected to a hydrothermal reaction at $180{ }^{\circ} \mathrm{C}$ for $6 \mathrm{~h}$. After cooling to room temperature, the solution was filtrated under vacuum and washed several times with distilled water. Finally, the solid was dried in the oven at $60^{\circ} \mathrm{C}$ for $24 \mathrm{~h}$.

\subsection{Synthesis of Nitrogen- and Sulfur-Functionalized Reduced Graphene Oxide}

Nitrogen- and sulfur-functionalized reduced graphene oxides (N,S-rGO) were prepared by the one-step hydrothermal method in the presence of ammonium thiocyanate [21]. GO (200 mg) and $\mathrm{NH}_{4} \mathrm{SCN}(300,450$, and $600 \mathrm{mg}$, samples were labeled as N,S-rGO300, $\mathrm{N}, \mathrm{S}-\mathrm{rGO} 450, \mathrm{~N}, \mathrm{~S}-\mathrm{rGO} 600$, respectively) were dispersed in $40 \mathrm{~mL}$ of distilled water by using an ultrasonic bath for $30 \mathrm{~min}$. Then, the mixture was put into a stainless steel autoclave heated to $180^{\circ} \mathrm{C}$ for $6 \mathrm{~h}$. Afterwards, the solid was filtered under vacuum, washed several times with distilled water, and dried at $60^{\circ} \mathrm{C}$ for $24 \mathrm{~h}$.

\subsection{Electrophoretic Deposition on the Copper Substrate}

Prior to EPD, the copper substrate was properly prepared by the removal of contaminations and copper oxides using hydrochloric acid, distilled water, and acetone. Then, GO, rGO, N,S-rGO precursors of coatings were dispersed in distilled water by using the ultrasonic bath for $0.5,1.5$, and $2 \mathrm{~h}$, respectively. The experimental setup for EPD was made of two parallel arranged copper electrodes separated from each other by around $1 \mathrm{~cm}$. The electrodes were connected to a power supply. This process was carried out using the following parameters: applied voltage $15 \mathrm{~V}$, time of deposition $15 \mathrm{~s}$, and a suspension concentration of $0.5 \mathrm{mg} \mathrm{mL}^{-1}$. After the electrolysis, the anodes were air-dried.

\subsection{Characterization}

All functionalized precursors of coatings were prepared from newly synthesized graphene oxide. Results for GO and rGO are meant to be reference data. Fourier Transform Infrared Spectroscopy (FTIR) of precursors of the coatings was conducted on the spectroscope PerkinElmer Frontier over a scanning range $550-4000 \mathrm{~cm}^{-1}$. X-ray diffraction (XRD) analysis was performed with Rigaku MiniFlex 600 in the range of angle $2^{\circ}-90^{\circ}(\mathrm{Cu}$ $\mathrm{K} \alpha$ radiation, $\lambda=1.54 \AA$ ). Characteristic crystallographic parameters such as an interlayer distance $\left(d_{002}\right)$, an in-plane crystallite size $\left(L_{a}\right)$, and an average crystallite width $\left(L_{\mathcal{c}}\right)$ were calculated using the following equations:

$$
\begin{gathered}
d_{002}=\lambda / 2 \cdot \sin \theta_{1} \\
L_{a}=1.84 \cdot \lambda / F W H M \cdot \cos \theta_{2}
\end{gathered}
$$




$$
L_{c}=0.89 \cdot \lambda / F W H M \cdot \cos \theta_{1}
$$

$\lambda$-radiation wavelength $(\AA)$;

$\theta_{1}-\left(\begin{array}{lll}0 & 0 & 2\end{array}\right)$ diffraction peak position $\left(^{\circ}\right)$;

$\theta_{2}-\left(\begin{array}{lll}1 & 0 & 0\end{array}\right)$ diffraction peak position $\left(^{\circ}\right)$;

FWHM - width at half height of the corresponding diffraction peak (rad).

Raman spectra were recorded on Horiba-Jobin Yvon microprobe apparatus excited by a $532 \mathrm{~nm}$ laser. A ratio of $\mathrm{I}_{\mathrm{D}} / \mathrm{I}_{\mathrm{G}}$ was calculated as the quotient area under the $\mathrm{D}$ peak and under the $G$ peak. As a result of the deconvolution of bands, the area under peaks was obtained. X-ray photoelectron spectroscopy (XPS) analysis was prepared by the Omicron NanoTechnology system at a pressure below $1.1 \times 10^{-8} \mathrm{mBa}$ and at room temperature. The Argus hemispherical spectrometer with a 128-channel collector was used for the energy measurement of photoelectrons. The photoelectrons were excited by a $\mathrm{Mg}-\mathrm{K} \alpha \mathrm{X}$-ray source operated at $15 \mathrm{keV}$ and $300 \mathrm{~W}$. Analysis of obtained results was performed using CASA XPS software package with Shirley background subtraction and least-square Gaussian-Lorentzian-GL(30) curve fitting algorithm. Calibration of measured spectra to the binding energy of $285 \mathrm{eV}$ for the $\mathrm{C} 1 \mathrm{~s}$ line was conducted. Zeta potential measurements of the graphene sheets in aqueous suspensions were carried out by using Malvern Zeta-Sizer. A contact angle of the coatings was determined by the goniometer Cam 200 KSV. The used liquid was distilled water (dosing volume of water of $1 \mu \mathrm{L})$. The surface topography of layers was defined by the Scanning Electron Microscope (SEM) and Atomic Force Microscopy (AFM). SEM images before the electrochemical tests were collected on the microscope Quanta FEG 400-FEI Company (SE detector, $15 \mathrm{kV}$ beam accelerating voltage), whereas SEM images after electrochemical tests and thickness of the coatings were obtained by SEM Microscope FEI Quanta FEG 250 with a SE-ETD detector (secondary electron-Everhart-Thornley detector), using $10 \mathrm{kV}$ beam accelerating voltage. Film thickness is the average value of all thickness measurements of the layers. AFM images were obtained using Bruker Catalyst by noncontact mode using Au coated silicon tips (scan rate- $0.273 \mathrm{~Hz}$ ). The cross-cut test was used to determine adhesion between the graphene coating and the metal substrate. With a knife, cuts separated by about $1 \mathrm{~mm}$ were made on the surface of coatings. After an adhesive tape was broken, on the basis of the number of detached graphene flakes, the adhesion of coatings was determined.

\subsection{Electrochemical Studies}

A sodium chloride solution $(3.5 \% \mathrm{NaCl})$ was used as the corrosive medium. Chloride ions are very aggressive for the copper substrate; therefore, it is important to assess the durability of the coatings in this environment. For evaluation of the protective properties of the graphene coatings, a potentiodynamic polarization was applied. Measurements were carried out by using a potentiostat, ATLAS-SOLLICH 0531 (Poland), connected to a cell containing the coated copper substrate as a working electrode, an $\mathrm{Ag} / \mathrm{AgCl}(\mathrm{KCl}$ saturated) reference electrode, and a platinum wire as a counter electrode. Electrochemical tests were performed twice for each sample, in a potential range of -0.1 to $0.1 \mathrm{~V}$ (vs. open circuit potential) with a scan rate of $0.5 \mathrm{mV} \mathrm{s}^{-1}$. To stabilize potential, every sample was immersed in the solution for $30 \mathrm{~min}$ before measurement.

Corrosion potential $\left(E_{\text {corr }}\right)$ and corrosion current density $\left(I_{\text {corr }}\right)$ were determined from the intersection of the anode and cathode curves. Corrosion rate $(C R)$ was calculated from the following equation (ASTM G59):

$$
C R=K \cdot I_{\text {corr }} \cdot \frac{E W}{d}
$$

$K$-corrosion rate constant $\left(\mathrm{mm}^{\mathrm{year}}{ }^{-1}\right)$;

$I_{\text {corr }}$-corrosion current density $\left(\mu \mathrm{A} \mathrm{cm}^{-2}\right)$;

$E W$ - equivalent weight, for $\mathrm{Cu} 31.7 \mathrm{~g}$;

$d$-density, $d_{\mathrm{Cu}}=8.97 \mathrm{~g} \mathrm{~cm}^{-3}$. 


\section{Results}

Functionalization of graphene oxides samples was carried out by prolonged reacting them with ammonium thiocyanate at $180^{\circ} \mathrm{C}$. Due to thermal instability, this compound decomposed to $\mathrm{NH}_{3}, \mathrm{CS}_{2}, \mathrm{H}_{2} \mathrm{~S}$, and $\mathrm{HSCN}$ [22], leading to a substitution of carbon and oxygen atoms in the basic structure of GOs with nitrogen and sulfur moieties. Ammonia contributed to the formation of pyridinic and pyrrolic sites [23], whereas $\mathrm{H}_{2} \mathrm{~S}$ as a sulfurizing agent created thiophene and thiol sites [24,25]. Moreover, oxygen released during the hydrothermal process caused oxidation of sulfur in these sites to $\mathrm{C}-\mathrm{SO}_{2}$, or $\mathrm{C}-\mathrm{SO}_{3} \mathrm{H}[26,27]$ (Scheme 1).

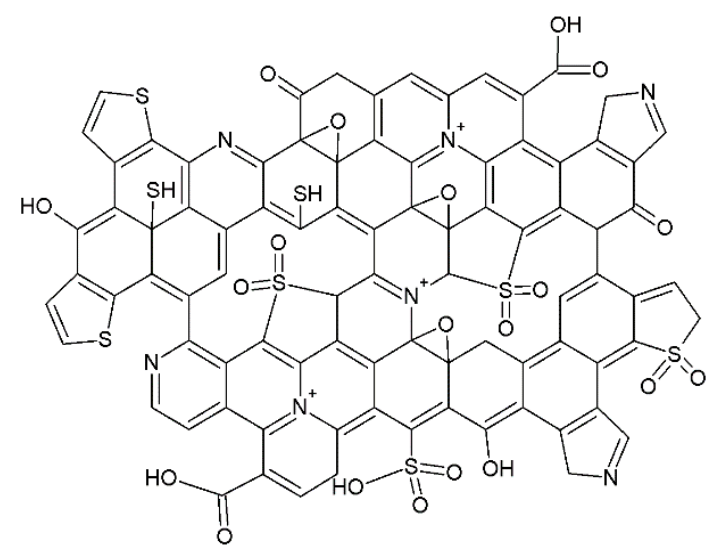

Scheme 1. Structure of nitrogen and sulfur functionalized reduced graphene oxide.

There is only one visible band, around $1500 \mathrm{~cm}^{-1}$, that could be clearly attributed to $\mathrm{C}=\mathrm{N}$ bonds. However, this very weak signal is apparently convoluted with the one attributed to $\mathrm{C}=\mathrm{C}$ bonds. This supposition was confirmed by the spectra of $\mathrm{GO}$ and reduced graphene oxide (rGO). The stretching energy of $1500 \mathrm{~cm}^{-1}$ is completely missing for GO (Figure 1a) because there are no $\mathrm{sp}^{2}$ domains in this structure. As the $\mathrm{sp}^{2}$ domains are restored by thermal reduction (rGO), the strong band at $1500 \mathrm{~cm}^{-1}$ shows up (Figure $1 \mathrm{~b}$ ). When the reduction of GO is conducted in the presence of ammonia, then the $1500 \mathrm{~cm}^{-1}$ band is also detectable in the spectra [9]. This time its intensity is weaker, probably due to the lower content of the $\mathrm{C}=\mathrm{C}$ domains, which could not be made up by the presence of $\mathrm{C}=\mathrm{N}$ bonds. The same bands are shown in Figure 1c-e become very minute due to further decrease in the $\mathrm{C}=\mathrm{C}$ content, which we relate to the presence of sulfur in addition to nitrogen atoms in the structure of the reduced graphene. The presence of some sulfur groups reveals the band at $1070 \mathrm{~cm}^{-1}$, in particular $\mathrm{C}=\mathrm{S}$ stretching vibrations, symmetrical stretching $\mathrm{SO}_{2}$ bands, and $\mathrm{SH}$ deforming vibrations. The intensity of this band is the highest for N,S-rGO300, and the lowest for N,S-GO600. The thiol groups should also give rise to a peak at $2600 \mathrm{~cm}^{-1}$, however, it was overlapped by a wide $\mathrm{OH}$ band.

During hydrothermal processes of sample preparation, thermal energy is sufficient to break the majority of $\mathrm{C}-\mathrm{O}$ bonds and replace some of them with $\mathrm{C}-\mathrm{N}$ or C-S bonds, allowing the distance to be shortened between graphene sheets and to preserve their parallel orientation. Well-resolved and sharp XRD reflections, shown in Figure 2, could be related to these reasonably ordered interlayer graphene packings. The lateral extent of the graphene layers $\left(L_{a}\right)$ was estimated from the width of $\left(\begin{array}{lll}1 & 0 & 0\end{array}\right)$ reflections at ca. $43^{\circ}$, while the stacking number of graphene sheets $\left(\mathrm{L}_{c}\right)$ was estimated from the width of $\left(\begin{array}{ll}0 & 0\end{array}\right)$ peaks at ca. $26^{\circ}$ (Table 1 ). One might have expected that the bulky sulfur groups would have helped to preserve the large distance between the graphene sheets; however, as the data show, it did not happen because the sulfur groups are mainly located near a periphery of the graphene structures (Scheme 1). There are a relatively large number of such sites due to the cleavage in the basal plane of GOs during the hydrothermal reductions as a result of an evolution of $\mathrm{CO}$ and $\mathrm{CO}_{2}$ [28] (lower lateral dimension) resulting in an increase in the edge-to-surface ratio. 


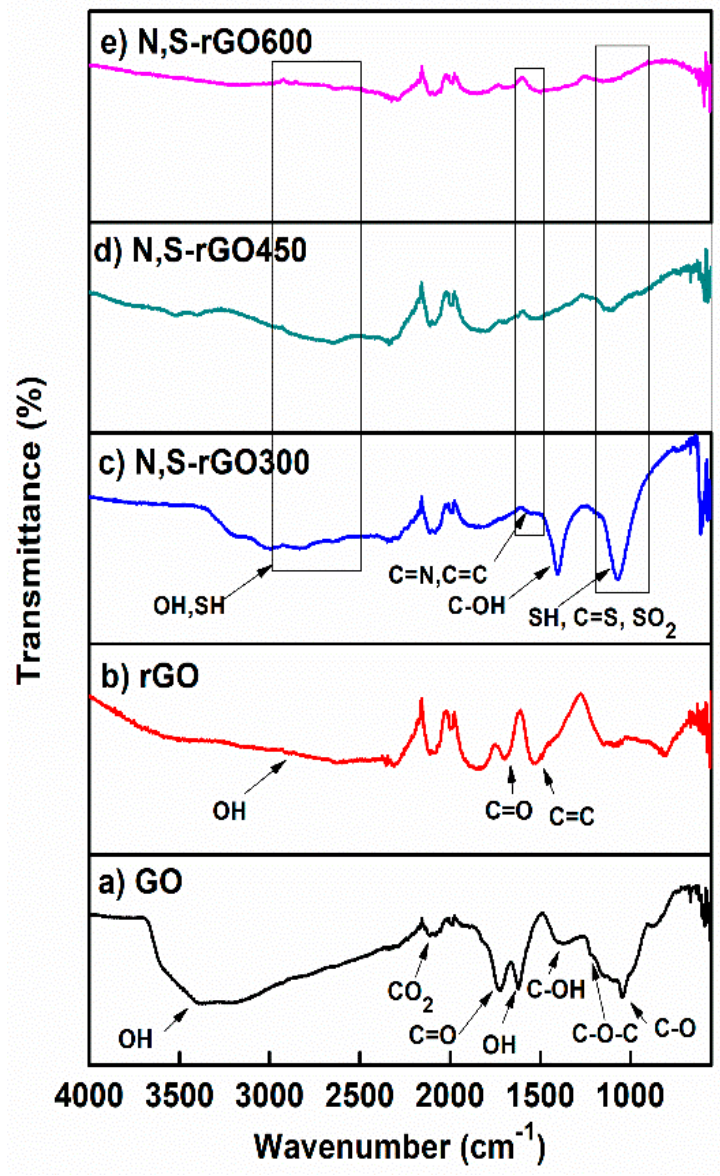

Figure 1. Fourier Transform Infrared Spectroscopy (FTIR) spectra for precursors of coatings. (a) GO, (b) rGO, (c) N,S-rGO300 (d) N,S-rGO450 (e) N,S-rGO600.

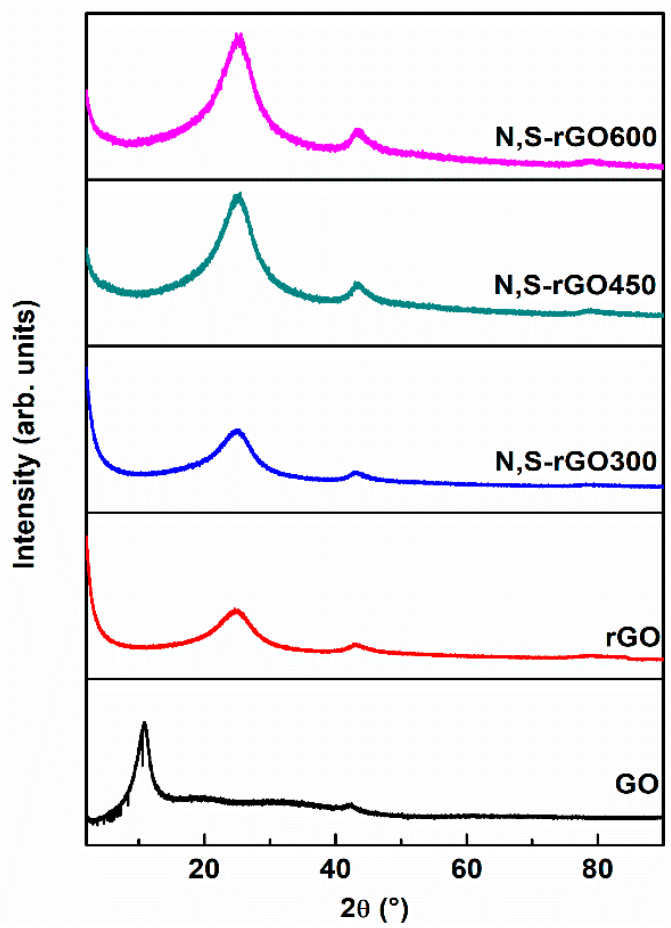

Figure 2. XRD patterns for precursors of coatings. 
Table 1. X-ray diffraction (XRD) parameters for precursors of coatings.

\begin{tabular}{ccccccc}
\hline Precursor of Coating & $\left.\mathbf{2} \Theta\left(^{\circ}\right) \mathbf{( 0 0 2}\right)$ & $\mathbf{d}(\AA)$ & $\mathbf{L}_{\mathbf{c}}(\AA)$ & $\mathbf{2} \Theta\left({ }^{\circ}\right)(\mathbf{1 0 0})$ & $\mathbf{L}_{\mathbf{a}}(\AA)$ & $\mathbf{I}_{\mathbf{D}} / \mathbf{I}_{\mathbf{G}}$ \\
\hline GO & 10.74 & 8.19 & 24.14 & 42.30 & 121.63 & 1.64 \\
rGO & 24.64 & 3.62 & 11.40 & 42.99 & 89.68 & 1.98 \\
N,S-rGO300 & 24.62 & 3.62 & 11.59 & 43.06 & 86.93 & 2.11 \\
N,S-rGO450 & 24.74 & 3.60 & 10.79 & 43.30 & 109.00 & 1.92 \\
N,S-rGO600 & 24.87 & 3.58 & 11.13 & 43.28 & 89.68 & 1.94 \\
\hline
\end{tabular}

The observations were further verified by Raman spectroscopy (Figure 3). The N,SrGO300 samples have the highest $\mathrm{I}_{\mathrm{D}} / \mathrm{I}_{\mathrm{G}}$ ratio, which confirms the largest concentration of internal and peripheral edges in the plane of these graphene platelets (Table 2). Moreover, the introduction of heteroatoms to the structure of graphene oxide also contributed to the increasing ratio compared to the nonmodified precursors of coatings.

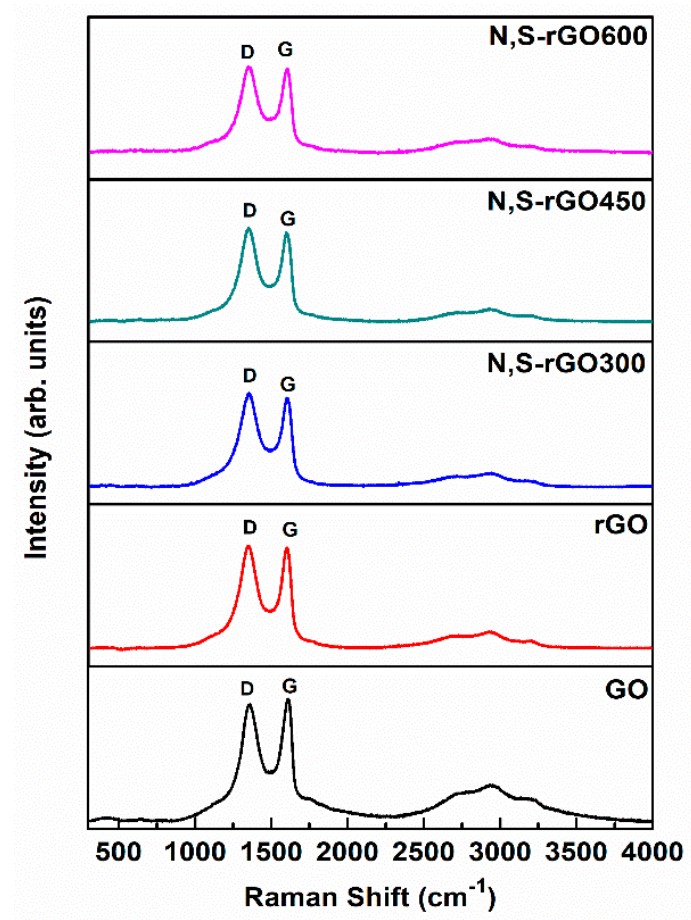

Figure 3. Raman spectra for precursors of coatings.

Table 2. XPS estimate of the surface relative $\mathrm{C}, \mathrm{O}, \mathrm{N}$ and $\mathrm{S}$ content of the precursors of coatings and coatings.

\begin{tabular}{ccccccccc}
\hline & \multicolumn{3}{c}{ Precursor of Coating } & \multicolumn{5}{c}{ Coating } \\
\cline { 2 - 9 } & $\mathbf{C ~ ( \% )}$ & $\mathbf{O ~ ( \% )}$ & $\mathbf{N ~ ( \% )}$ & $\mathbf{S ~ ( \% )}$ & $\mathbf{C ~ ( \% )}$ & $\mathbf{O ~ ( \% )}$ & $\mathbf{N ~ ( \% )}$ & $\mathbf{S ~ ( \% )}$ \\
\hline GO & 41.7 & 58.3 & - & - & 51.5 & 48.5 & - & - \\
rGO & 66.8 & 33.2 & - & - & 69.6 & 30.4 & - & - \\
N,S-rGO300 & 66.7 & 29.8 & 1.6 & 1.9 & 60.5 & 33.4 & 5.2 & 0.9 \\
N,S-rGO450 & 67.5 & 28.5 & 1.9 & 2.1 & 61.6 & 34.0 & 3.6 & 0.8 \\
N,S-rGO600 & 66.6 & 26.8 & 3.7 & 2.9 & 61.9 & 34.3 & 3.5 & 0.3 \\
\hline
\end{tabular}

The elemental compositions of the studied graphene precursors and coatings were studied by the XPS technique (Figures S1 and S2). The high-resolution C1s spectra of the samples functionalized with nitrogen and sulfur were assigned to $\mathrm{C}=\mathrm{C}(\sim 284.59 \mathrm{eV})$, C-N/C-S/C-O (hydroxyl and epoxy bonds) ( 285.44 eV), C=O ( 287.76 eV), and O$\mathrm{C}=\mathrm{O}(\sim 289.58 \mathrm{eV})$ [29]. The high-resolution N1s spectra show three peaks at $\sim 397.73$, $\sim 399.48, \sim 401.00 \mathrm{eV}$, which correspond to pyridinic-N, pyrrolic-N, and graphitic-N, respec- 
tively $[30,31]$. The spectra of S2p are composed of three components, which are attributed to thiolic-S [32] and thiophenic-S [33] and oxidized forms of C-SO $(x=2,3)$ [29].

The percentage chemical compositions of the precursors and coatings are presented in Table 2. These results show that during the hydrothermal reduction, the deoxygenation of the samples took place, which resulted in a partial restoration of the $\mathrm{sp}^{2}$ hybridization of the carbon atoms (see Figure 1-intensity of functional oxygen groups peaks was significantly decreased). These results, relevant to the GO and rGO samples, are in accordance with the one we have recently published [16]. Moreover, the analysis of the results also shows that the deoxygenation of the graphene platelets deepens during the formation (electrodeposition) of the coatings. This is probably due to the oxidative Kolbe's reaction, simultaneously causing an increase in the concentration of nitrogen compared to precursors of coatings. On the other hand, as expected, the concentration of heteroatoms in the structure of functionalized graphene platelets increases with concentration of ammonium thiocyanate used for the synthesis (an increase in the $\mathrm{I}_{\mathrm{D}} / \mathrm{I}_{\mathrm{G}}$ ratio for the functionalized samples in comparison to nonmodified samples). During electroformation of the coatings, many thiophene and thiols were oxidized to carbon bound $-\mathrm{SO}_{2}$ groups, although some sulfur was lost due to $\mathrm{SO}_{2}$ gas release.

Electrophoretic deposition requires stable dispersions. Due to the large interlayer distance for graphene oxide maintained by weak interactions, the stable suspension of graphene oxide was easily produced by $0.5 \mathrm{~h}$ treatment in an ultrasonic bath. Reduced graphene oxide samples were characterized by significantly lower interlayer spacings and thus, stronger interactions between layers. This caused the obtention of uniform suspension more difficult, simultaneously contributing to prolonged ultrasonic treatment (around $2 \mathrm{~h}$ ). The obtained suspensions were stable due to the Zeta potential $(\zeta)$ being lower than $-30 \mathrm{mV}$ [34]. Measured potentials were $-47.6,-41.4,-59.5,-55.7$, and $-50.5 \mathrm{mV}$ for GO, rGO, N,S-rGO300, N,S-rGO450, and N,S-rGO600, respectively.

As expected, the Zeta potential for rGO is higher (less negative) than that for GO. However, in the case of functionalized graphene oxide samples, the Zeta potential is much lower than that for $\mathrm{GO}$ and $\mathrm{rGO}$ due to the presence of the $\mathrm{C}-\mathrm{SO}_{2}$ groups. Moreover, an increase in the potential from N,S-rGO300 to N,S-rGO600 samples results from the increasing content of graphitic nitrogen $(0.9 \%, 1.2 \%$, and $3.0 \%$ for N,S-rGO300, N,S-rGO450, and N,S-rGO600), whose positive charge compensates the negative charge of $\mathrm{C}^{-\mathrm{SO}_{2}}$ groups.

The roughness of the coatings was estimated by the AFM (Figure 4 and Table 3). The results show that the coatings obtained from the GO precursor were the most rough, probably due to intensive $\mathrm{CO}_{2}$ release during electrolysis. The other precursors were not subjected to the destructive $\mathrm{CO}_{2}$ evolution because they contained a substantially lower concentration of oxygen in their structures. The same observation is also true for the functionalized coatings.

Table 3. Contact angle values and surface roughness parameters for graphene coatings.

\begin{tabular}{cccc}
\hline \multirow{2}{*}{ Coating } & Contact Angle Value $\left(^{\circ}\right)$ & \multicolumn{2}{c}{ Surface Roughness Parameters } \\
\cline { 3 - 4 } & & Sq (nm) & Sa (nm) \\
\hline Cu & $58.80 \pm 0.70$ & - & - \\
GO & $59.50 \pm 2.25$ & 478.1 & 366.0 \\
rGO & $109.23 \pm 1.08$ & 278.7 & 219.3 \\
N,S-rGO300 & $141.07 \pm 1.87$ & 267.7 & 222.2 \\
N,S-rGO450 & $119.06 \pm 0.98$ & 261.5 & 215.8 \\
N,S-rGO600 & $133.97 \pm 1.28$ & 311.2 & 254.3 \\
\hline
\end{tabular}

The low wettability of the protective coatings is a crucial property to fend off water. The measured contact angles show (Table 3 and Figure 5) that all functionalized coatings are highly hydrophobic and should effectively repel water from their surface. 

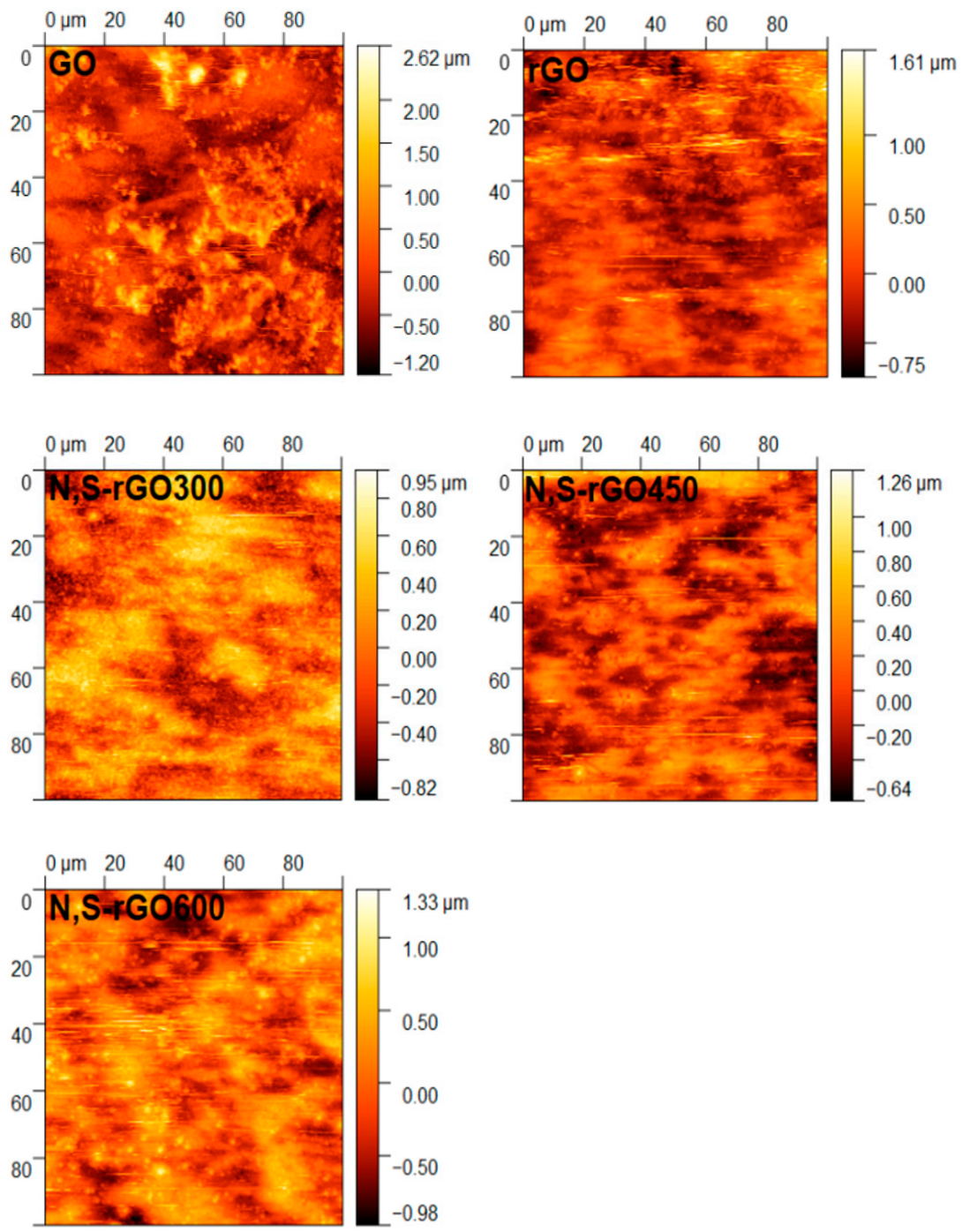

Figure 4. Atomic Force Microscopy (AFM) images for graphene coatings.
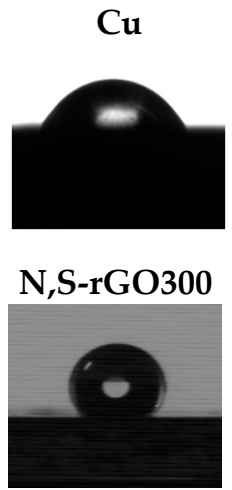
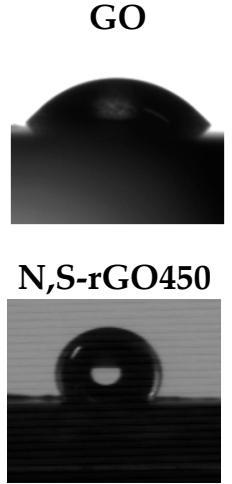
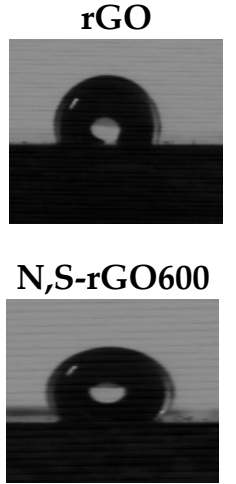

Figure 5. The contact angle images.

SEM images of all coatings, before and after electrochemical studies, are presented in Figure 6. In general, their surfaces were smooth and uniform with a few wrinkles or minute pores. The average thickness of all coatings was $1.81 \pm 0.04 \mu \mathrm{m}$ (Figure 7). The coatings were subjected to partial oxidation due to anodic polarization, which resulted in their further smoothing down. Figure 8 also shows the cross-cut adhesion test results for the coatings. The large number of detached flakes indicates that the GO coating was the 
least adhesive to the copper substrate, whereas the other coatings possessed reasonable surface grip to the metal.
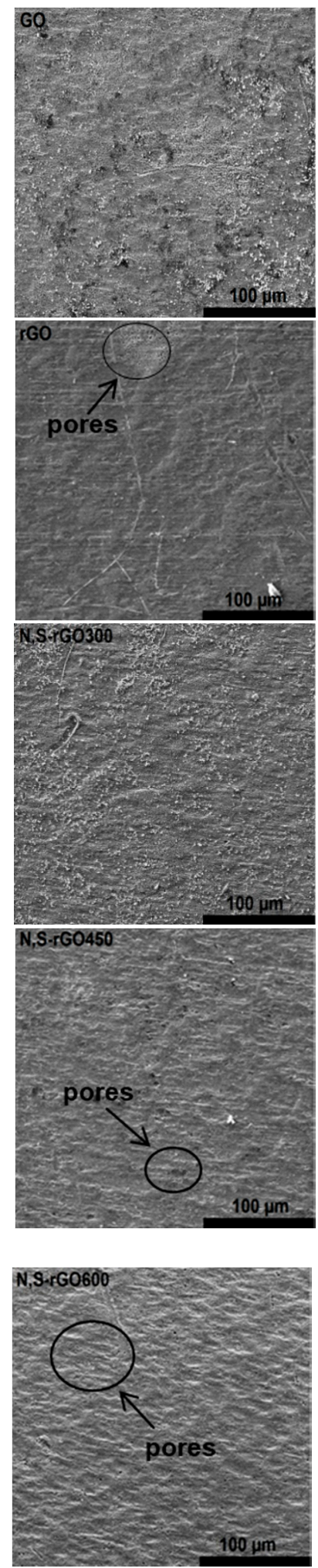

(a)
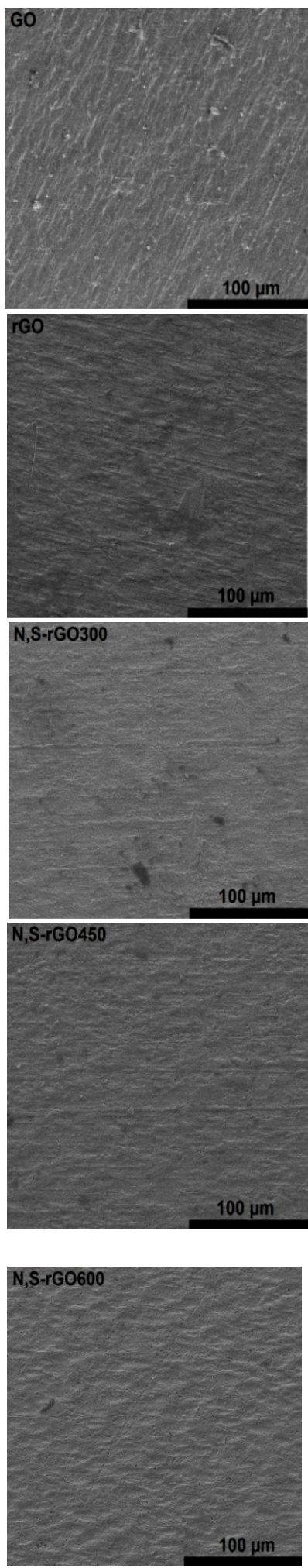

(b)

Figure 6. Scanning Electron Microscope (SEM) images for graphene coatings: (a) before corrosion test; (b) after corrosion test. 


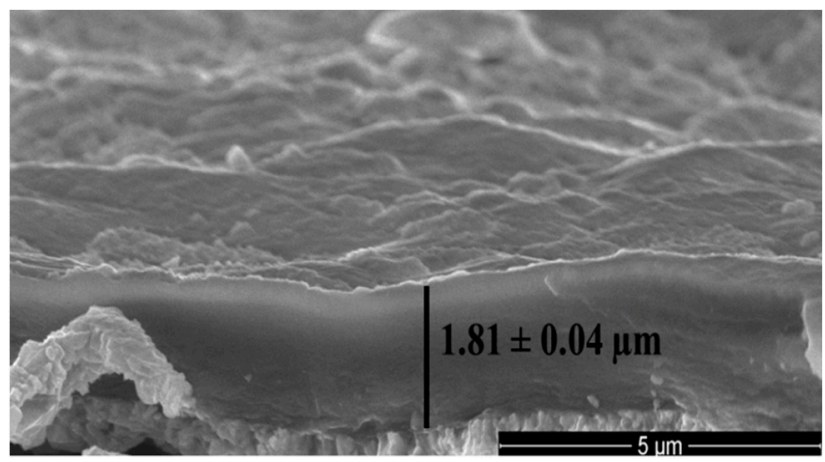

Figure 7. The thickness of graphene coatings.

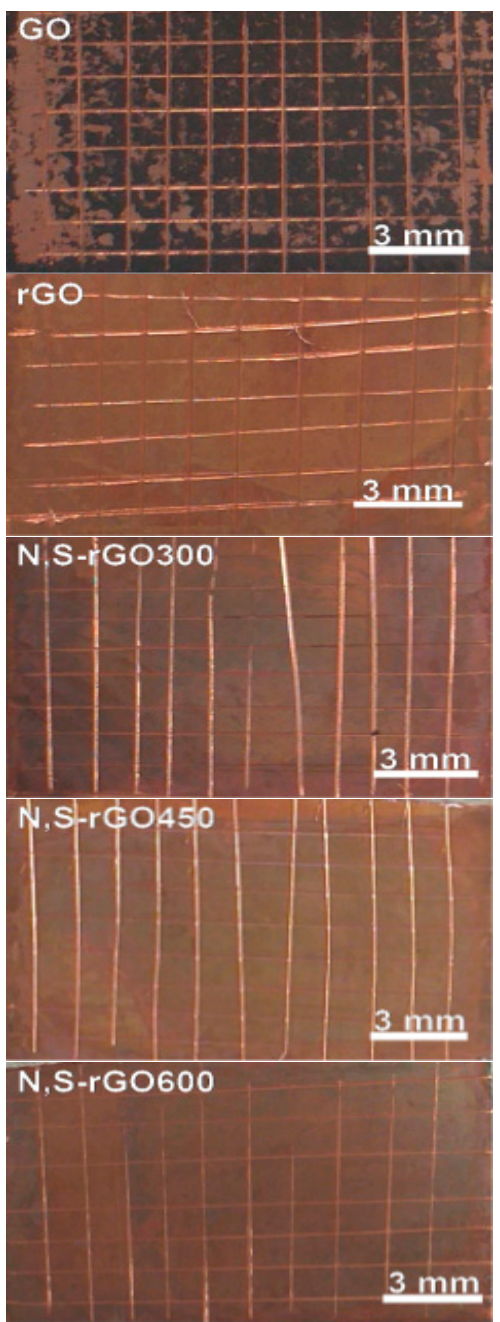

(a)

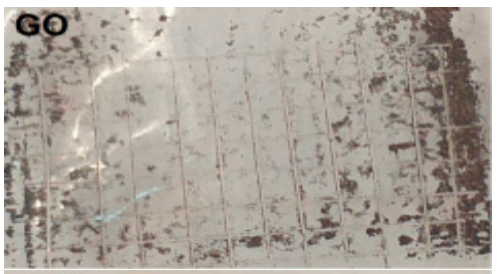

rGO

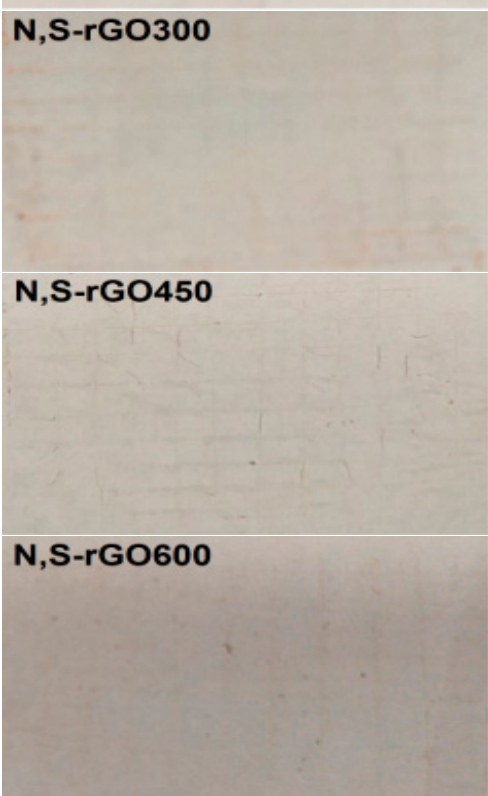

(b)

Figure 8. Photographs of graphene coatings: (a) after cross-cut test; (b) view of tape after breaking from coatings.

The corrosion resistance of all coating against 3.5\% sodium chloride solution was tested by a potentiodynamic polarization method. The results are presented by the Tafel plots in Figure 9, and the Tafel parameters are shown in Table 4. 


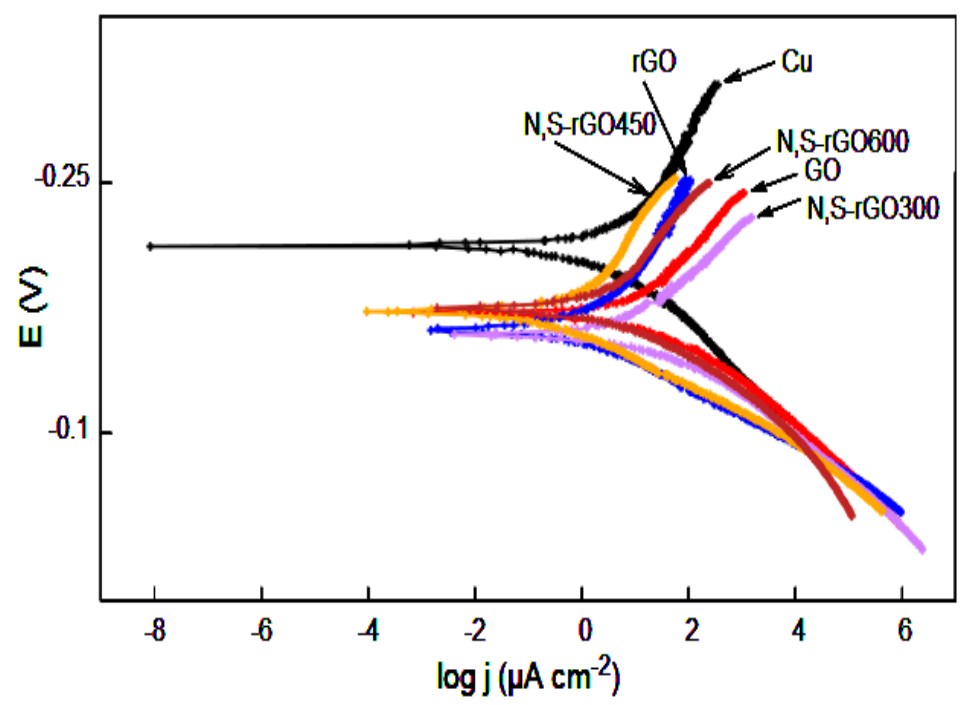

Figure 9. Polarization curves for copper and graphene coatings.

Table 4. Corrosion parameters for bare copper and graphene coatings.

\begin{tabular}{cccc}
\hline Coating & $\mathbf{I}\left(\boldsymbol{\mu} \mathbf{A ~ \mathbf { ~ c m } ^ { - 2 } )}\right.$ & E $(\mathbf{V})$ & Corrosion Rate $\left(\mathbf{m m}_{\text {year }} \mathbf{- 1}^{\mathbf{1}}\right)$ \\
\hline $\mathrm{Cu}$ & 4.42 & -0.220 & 0.051 \\
\hline $\mathrm{GO}$ & 11.12 & -0.188 & 0.128 \\
\hline $\mathrm{rGO}$ & 1.90 & -0.152 & 0.022 \\
\hline $\mathrm{N}, \mathrm{S}-\mathrm{rGO} 300$ & 7.28 & -0.182 & 0.084 \\
\hline $\mathrm{N}, \mathrm{S}-\mathrm{rGO} 450$ & 0.16 & -0.182 & 0.002 \\
\hline N,S-rGO600 & 0.90 & -0.186 & 0.010 \\
\hline
\end{tabular}

As can be seen in Figure 9, all coated samples reduced electrochemical activity. The $E_{c o r r}$ shifted towards more positive values for all coated samples, indicating that coatings probably act as a barrier separating copper from the aggressive environment. However, the hydrophilic nature of the graphene oxide allows penetration of the GO coatings by water, causing oxidation of copper. Moreover, the high current density stems also from the partial or complete oxidation of carbon, which may finally result in the decomposition of the coatings.

$$
\begin{gathered}
\mathrm{C}-\mathrm{C}+2 \mathrm{H}_{2} \mathrm{O} \rightarrow \mathrm{OH}-\mathrm{C}-\mathrm{C}-\mathrm{OH}+2 \mathrm{H}^{+}+2 \mathrm{e}^{-} \\
\mathrm{C}+2 \mathrm{H}_{2} \mathrm{O} \rightarrow \mathrm{CO}_{2}+4 \mathrm{H}^{+}+4 \mathrm{e}^{-}
\end{gathered}
$$

In the case of the rGO coatings, their hydrophobicity makes them an impenetrable water barrier. Therefore, the measured corrosion current stemmed only from the oxidation of carbon. Thanks to this, the surface of these coatings became smoother after the electrochemical tests.

In our previous work, we showed that the nitrogen-functionalized graphene oxide coatings had protective properties, but these were comparable to the anticorrosion properties of the reduced graphene oxide coatings. Nitrogen groups exhibiting catalytic properties towards the oxygen reduction reaction were responsible for this behavior. The coatings produced in this study contain a substantial amount of $\mathrm{C}-\mathrm{SO}_{2}$ groups formed as a result of the oxidation of thiophene groups during EPD. Nitrogen that is also present in the structure can effectively catalyze the oxidation of these groups to $\mathrm{C}-\mathrm{SO}_{3} \mathrm{H}$ by oxygen from the air, so oxygen can no longer depolarize the copper metal. The corrosion protection mechanism of the graphene coatings is presented in Figure 10. 


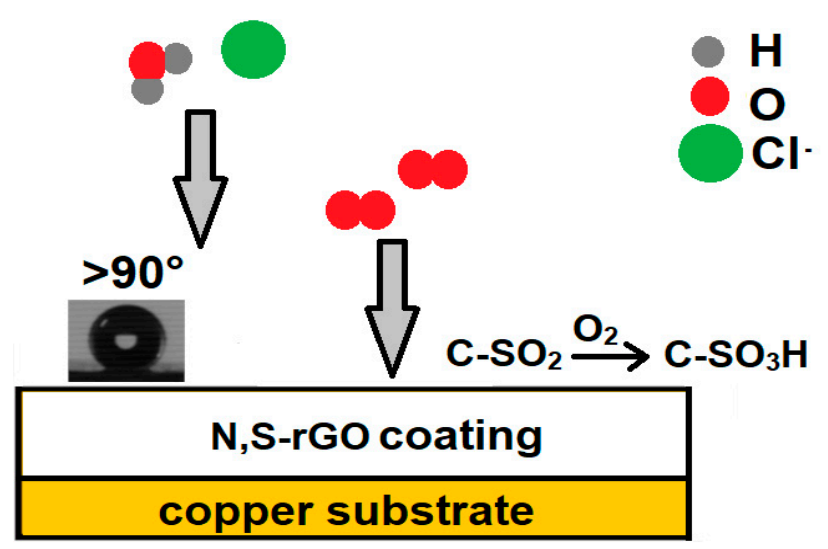

Figure 10. The protection mechanism of functionalized graphene coatings.

\section{Conclusions}

The introduction of nitrogen and sulfur groups to the graphene oxide structure contributed to the improved corrosion resistance of graphene coatings produced by EPD on the copper substrate. These coatings had numerous $\mathrm{C}-\mathrm{SO}_{2}$ groups in their structures, which formed as a result of the oxidation of thiophene groups. Nitrogen can effectively catalyze the oxidation of these groups to $\mathrm{C}-\mathrm{SO}_{3} \mathrm{H}$ with oxygen from the air.

Supplementary Materials: The following are available online at https:/ /www.mdpi.com/1996-1 944/14/6/1410/s1: Figure S1: XPS spectra for precursors of coatings. Figure S2: XPS spectra for graphene coatings.

Author Contributions: Conceptualization, K.O.; formal analysis, K.O.; investigation, K.O. and J.K.; resources, K.O.; data curation, K.O. and J.K.; writing-original draft preparation, K.O.; writingreview and editing, M.L.; supervision, M.L.; project administration, K.O. All authors have read and agreed to the published version of the manuscript.

Funding: This research received no external funding.

Institutional Review Board Statement: Not applicable.

Informed Consent Statement: Not applicable.

Data Availability Statement: Data are contained within the article and supplementary material.

Conflicts of Interest: The authors declare no conflict of interest.

\section{References}

1. Zhou, F.; Li, Z.; Shenoy, G.J.; Li, L.; Liu, H. Enhanced room-temperature corrosion of copper in the presence of graphene. ACS Nano 2013, 7, 6939-6947. [CrossRef]

2. Braeuninger-Weimer, P.; Burton, O.J.; Zeller, P.; Amati, M.; Gregoratti, L.; Weatherup, R.S.; Hofmann, S. Crystal Orientation Dependent Oxidation Modes at the Buried Graphene-Cu Interface. Chem. Mater. 2020, 32, 7766-7776. [CrossRef]

3. Chen, S.; Brown, L.; Levendorf, M.; Cai, W.; Ju, S.-Y.; Edgeworth, J.; Li, X.; Magnuson, C.W.; Velamakanni, A.; Piner, R.D.; et al. Oxidation resistance of graphene-coated $\mathrm{Cu}$ and $\mathrm{Cu}$ Ni alloy. ACS Nano 2011, 5, 1321-1327. [CrossRef]

4. Singh Raman, R.K.; Chakraborty Banerjee, P.; Lobo, D.E.; Gullapalli, H.; Sumandasa, M.; Kumar, A.; Choudhary, L.; Tkacz, R.; Ajayan, P.M.; Majumder, M. Protecting copper from electrochemical degradation by graphene coating. Carbon N. Y. 2012, 50, 4040-4045. [CrossRef]

5. Kirkland, N.T.; Schiller, T.; Medhekar, N.; Birbilis, N. Exploring graphene as a corrosion protection barrier. Corros. Sci. 2012, 56, 1-4. [CrossRef]

6. Police, A.K.R.; Chennaiahgari, M.; Boddula, R.; Vattikuti, S.V.P.; Mandari, K.K.; Chan, B. Single-step hydrothermal synthesis of wrinkled graphene wrapped $\mathrm{TiO} 2$ nanotubes for photocatalytic hydrogen production and supercapacitor applications. Mater. Res. Bull. 2018, 98, 314-321. [CrossRef]

7. Madhuri, C.; Manohara Reddy, Y.V.; Prabhakar Vattikuti, S.V.; Svorc, L'; Shim, J.; Madhavi, G. Trace-level determination of amlodipine besylate by immobilization of palladium-silver bi-metallic nanoparticles on reduced graphene oxide as an electrochemical sensor. J. Electroanal. Chem. 2019, 847, 113259-113267. [CrossRef] 
8. Vattikuti, S.V.P.; Nagajyothi, P.C.; Devarayapalli, K.C.; Shim, J. Depositing reduced graphene oxide onto tungsten disulfide nanosheets: Via microwave irradiation: Confirmation of four-electron transfer-assisted oxygen reduction and methanol oxidation reaction. New J. Chem. 2020, 44, 10638-10647. [CrossRef]

9. An, S.J.; Zhu, Y.; Lee, S.H.; Stoller, M.D.; Emilsson, T.; Park, S.; Velamakanni, A.; An, J.; Ruoff, R.S. Thin film fabrication and simultaneous anodic reduction of deposited graphene oxide platelets by electrophoretic deposition. J. Phys. Chem. Lett. 2010, 1, 1259-1263. [CrossRef]

10. Raza, M.A.; Rehman, Z.U.; Ghauri, F.A.; Ahmad, A.; Ahmad, R.; Raffi, M. Corrosion study of electrophoretically deposited graphene oxide coatings on copper metal. Thin Solid Films 2016, 620, 150-159. [CrossRef]

11. Bagherzadeh, M.; Ghahfarokhi, Z.S.; Yazdi, E.G. Electrochemical and surface evaluation of the anti-corrosion properties of reduced graphene oxide. RSC Adv. 2016, 6, 22007-22015. [CrossRef]

12. He, W.; Zhu, L.; Chen, H.; Nan, H.; Li, W.; Liu, H.; Wang, Y. Electrophoretic deposition of graphene oxide as a corrosion inhibitor for sintered NdFeB. Appl. Surf. Sci. 2013, 279, 416-423. [CrossRef]

13. Madhan Kumar, A.; Suresh Babu, R.; Obot, I.B.; Gasem, Z.M. Fabrication of nitrogen doped graphene oxide coatings: Experimental and theoretical approach for surface protection. RSC Adv. 2015, 5, 19264-19272. [CrossRef]

14. Ren, S.; Cui, M.; Li, W.; Pu, J.; Xue, Q.; Wang, L. N-doping of graphene: Toward long-term corrosion protection of Cu. J. Mater. Chem. A 2018, 6, 24136-24148. [CrossRef]

15. Lai, L.; Potts, J.R.; Zhan, D.; Wang, L.; Poh, C.K.; Tang, C.; Gong, H.; Shen, Z.; Lin, J.; Ruoff, R.S. Exploration of the active center structure of nitrogen-doped graphene-based catalysts for oxygen reduction reaction. Energy Environ. Sci. 2012, 5, 7936-7942. [CrossRef]

16. Ollik, K.; Rybarczyk, M.; Karczewski, J.; Lieder, M. Fabrication of anti-corrosion nitrogen doped graphene oxide coatings by electrophoretic deposition. Appl. Surf. Sci. 2019, 499, 143914-143920. [CrossRef]

17. Li, J.; Liu, J.; Yin, S.; Liu, Y.; Li, J.; Cen, W.; Chu, Y. Promotion mechanism of pyridine N-doped carbocatalyst for SO2 oxidation. RSC Adv. 2016, 6, 86316-86323. [CrossRef]

18. Hou, M.; Zhang, X.; Yuan, S.; Cen, W. Double graphitic-N doping for enhanced catalytic oxidation activity of carbocatalysts. Phys. Chem. Chem. Phys. 2019, 21, 5481-5488. [CrossRef]

19. Marcano, D.C.; Kosynkin, D.V.; Berlin, J.M.; Sinitskii, A.; Sun, Z.; Slesarev, A.; Alemany, L.B.; Lu, W.; Tour, J.M. Improved synthesis of graphene oxide. ACS Nano 2010, 4, 4806-4814. [CrossRef]

20. Zhou, Y.; Bao, Q.; Tang, L.A.L.; Zhong, Y.; Loh, K.P. Hydrothermal dehydration for the "green" reduction of exfoliated graphene oxide to graphene and demonstration of tunable optical limiting properties. Chem. Mater. 2009, 21, 2950-2956. [CrossRef]

21. Su, Y.; Zhang, Y.; Zhuang, X.; Li, S.; Wu, D.; Zhang, F.; Feng, X. Low-temperature synthesis of nitrogen/sulfur co-doped three-dimensional graphene frameworks as efficient metal-free electrocatalyst for oxygen reduction reaction. Carbon N. Y. 2013, 62, 296-301. [CrossRef]

22. Ohta, M.; Hirai, S.; Kato, H.; Sokolov, V.V.; Bakovets, V.V. Thermal decomposition of NH4SCN for preparation of Ln 2 S3 (Ln = La and Gd) by sulfurization. Mater. Trans. 2009, 50, 1885-1889. [CrossRef]

23. Shang, Y.; Xu, H.; Li, M.; Zhang, G. Preparation of N-Doped Graphene by Hydrothermal Method and Interpretation of N-Doped Mechanism. Nano 2017, 12, 1-9. [CrossRef]

24. Campaigne, E.; Foye, W.O. The synthesis of 2,5-diarylthiophenes. J. Org. Chem. 1952, 17, 1405-1412. [CrossRef]

25. Sathyadevi, P.; Chen, Y.J.; Wu, S.C.; Chen, Y.H.; Wang, Y.M. Reaction-based epoxide fluorescent probe for in vivo visualization of hydrogen sulfide. Biosens. Bioelectron. 2015, 68, 681-687. [CrossRef]

26. Montoya Sánchez, N.; de Klerk, A. Autoxidation of aromatics. Appl. Petrochem. Res. 2018, 8, 55-78. [CrossRef]

27. Bagiyan, G.A.; Koroleva, I.K.; Soroka, N.V.; Ufimtsev, A.V. Oxidation of thiol compounds by molecular oxygen in aqueous solutions. Russ. Chem. Bull. 2003, 52, 1135-1141. [CrossRef]

28. Hu, K.; Xie, X.; Szkopek, T.; Cerruti, M. Understanding Hydrothermally Reduced Graphene Oxide Hydrogels: From Reaction Products to Hydrogel Properties. Chem. Mater. 2016, 28, 1756-1768. [CrossRef]

29. Kannan, A.G.; Zhao, J.; Jo, S.G.; Kang, Y.S.; Kim, D.W. Nitrogen and sulfur co-doped graphene counter electrodes with synergistically enhanced performance for dye-sensitized solar cells. J. Mater. Chem. A 2014, 2, 12232-12239. [CrossRef]

30. Yang, S.; Zhi, L.; Tang, K.; Feng, X.; Maier, J.; M??llen, K. Efficient synthesis of heteroatom (N or S)-doped graphene based on ultrathin graphene oxide-porous silica sheets for oxygen reduction reactions. Adv. Funct. Mater. 2012, 22, 3634-3640. [CrossRef]

31. Pendashteh, A.; Palma, J.; Anderson, M.; Marcilla, R. NiCoMnO4 nanoparticles on N-doped graphene: Highly efficient bifunctional electrocatalyst for oxygen reduction/evolution reactions. Appl. Catal. B Environ. 2017, 201, 241-252. [CrossRef]

32. Adams, L.; Oki, A.; Grady, T.; McWhinney, H.; Luo, Z. Preparation and characterization of sulfonic acid-functionalized singlewalled carbon nanotubes. Phys. E Low-Dimens. Syst. Nanostruct. 2009, 41, 723-728. [CrossRef] [PubMed]

33. Zhang, M.; Hong, W.; Xue, R.; Li, L.; Huang, G.; Xu, X.; Gao, J.; Yan, J. Nitrogen/sulfur dual-doped reduced graphene oxide supported CuFeS2as an efficient electrocatalyst for the oxygen reduction reaction. New J. Chem. 2018, 42, 2081-2088. [CrossRef]

34. Mehrali, M.; Sadeghinezhad, E.; Tahan Latibari, S.; Mehrali, M.; Togun, H.; Zubir, M.N.M.; Kazi, S.N.; Metselaar, H.S.C. Preparation, characterization, viscosity, and thermal conductivity of nitrogen-doped graphene aqueous nanofluids. J. Mater. Sci. 2014, 49, 7156-7171. [CrossRef] 